
not just food, FlorenceSWIF2015

\title{
New Paradigms For A Sustainable Well-Being
}

\author{
Alberto Manelli* \\ Management department - Università Politecnica delle Marche di Ancona
}

\begin{abstract}
The achievement of "food security" involves the companies and their productive capacity. As well, the role played by the financial and commodities markets and their operators - commercial, financial and credit intermediaries- is important for the achievement of a new sustainability. Therefore, the "agricultural crisis" is based, principally on agricultural and environmental questions, but also on economic and markets issues.

This paper represents an attempt to extend the scientific research on new paradigms of sustainable well-being variables, at least in part neglected or still considered prejudicially harmful, compared to environmental issues.

Moreover, the economic dimension of sustainable well-being is investigated especially, referring to the financial market and its rules, as well as the agricultural products and the modalities to define their price.

(C) 2016 The Authors. Published by Elsevier B.V. This is an open access article under the CC BY-NC-ND license

(http://creativecommons.org/licenses/by-nc-nd/4.0/).

Peer-review under responsibility of Fondazione Simone Cesaretti

Keywords: Food security, financial market, commodity market, futures, farmer market price
\end{abstract}

\section{The related context}

The definition and creation of a new "sustainable well-being" is a challenge designed to always involve a growing number of scholars in various areas of research in the coming years. In fact, the identification and the study of the variables determining such an ambitious outcome cannot include only the environmental matters. It is now quite evident that they are numerous and articulated profiles and sectors that are decisive in achieving a balance between the need for growth - economic, employment, social, etc.. - and needs to respect the present and future environment, in primis, but also of other context conditions, such as different cultures, religions, traditions, food quality, etc.. (Cesaretti et Al., 2013).

\footnotetext{
* Corresponding author.

E-mail address: albertomanelli@tiscali.it
} 
Therefore, the achievement of a "effective and comprehensive" sustainability requires a systemic vision of the variables considered, so that the interaction between them leads to the simultaneous presence of the three conditions (Elkington 1997):

- environmental sustainability, as the ability to ensure the long-environment functions as a supplier of resources, waste receiver and direct source of utility;

- economic sustainability, becoming from a long-term growth of economic indicators and the achievement of adequate returns and paying the risk borne by all parties involved in the creating value process;

- social sustainability, achieved through the ability to ensure conditions of human well-being evenly distributed.

Each programmatic choice adopted must converge towards the simultaneous presence of all those three conditions of sustainability. Indeed, the lack, in turn, of one of these distinct conditions implies the achievement of a sustainability "partial" defined, respectively, as "livable" in the absence of economic sustainability, or "feasible" in the absence of social, or finally, "fair" in the absence of environmental sustainability. But in none of the cases now reported are unable to come to a full sustainability, and to a sustainable well-being.

Figure 1 - The interconnections between the dimensions of sustainable development

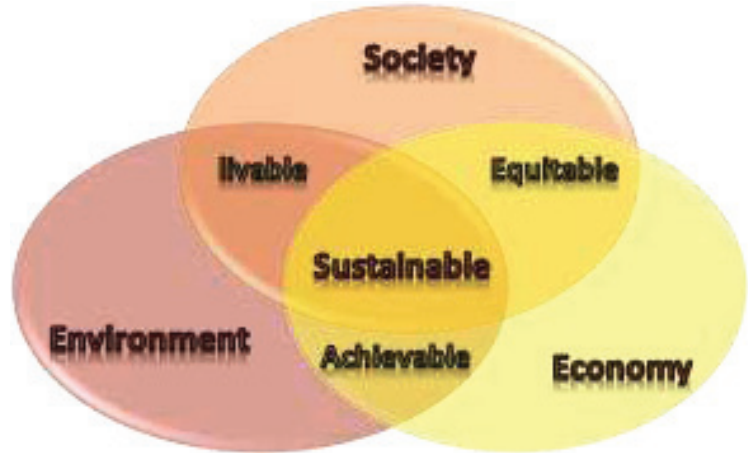

\section{Source: Own elaboration drawing on Sogesid website}

So, obviously, the many faces related to the concept of sustainable well-being they also challenge students of business subjects. First, considering the decisive role played by companies in this area, at a time when their priority is no longer the simple profit maximization, but the value growth (Manelli and Pace, 2009). In addition to typical economic parameters (efficiency, productivity, competitiveness, etc.), in fact, it emerges with increasing relevance the social aspects (the "corporate social responsibility" is a concept now learnt by entrepreneurs), environmental variables, the link with the territory and so on. But equally important for the achievement of a new sustainability is the role played by financial and commodities markets, as well as by their operators, with particular reference to commercial, financial and credit intermediaries.

Therefore, there is no doubt, that the first condition to ensure the individual as different social groups, to the territories as well as to businesses (literature, is that the economic environment is that, in this sense, shows a broad convergence in the field), as the "survival."

The "food crisis" has therefore a double meaning: quantitative and qualitative. The most important question to ask at this point is how much and how to grow the global supply of food.

On the other hand, to put into a right context the analysis to be carried out is necessary, highlighting the existence of three "major development trajectories" (Van der Ploeg, 2009) which is currently subject to world agriculture and which arises in opposition among them:

- a strong trend to industrialization, which in turn characterized by cancellation of all space-time link between production and consumption, of the breakdown in isolated phases of production processes and their subsequent reassembly according to a coordination unit, to the point to assimilate food to a "built" industrial good and not produced and processed (Lang and Heasman, 2004);

- a reaffirmation of the "farmer" model to run the small and medium enterprises aimed primarily at improving the living conditions of the farmers themselves and characterized by the use of family labor or belonging to the rural community, from direct ownership of farmland and other factors of production, and the need to maintain the ecological capital intact in the future. However, the evident benefit to be achieved in terms of the production 
quality and of the growth of the viability of individual companies is likely to be offset by a greater departure from the exchange markets (Johnson, 2004);

- a reduction in the levels of agricultural production - or at best hypothesis the active contain of the same -, resulting in the output of the labor force by sector and re-use of funds released from other activities, especially financial. In the first place, this phenomenon is present in sub-Saharan Africa due to production processes which are absolutely not efficient with respect to the sale prices achieved on the markets; then, in the peri-urban areas of large cities in expansion in relation to a speculation that can make easier to achieve gains with respect to agriculture; and finally, also in Europe, in general and in industrialized countries, as a result of restrictions imposed by government policy decisions have occurred over time (think, for example, the criteria involving setaside set-aside of arable land).

There are other constraints at the beginning of the agricultural chain able to influence the production, creating a situation of scarcity. Among them, the main question to be monitored carefully is related to the water availability.Therefore, it is clear that if the food safety can be defined as the possibility of access by all to a quantity of food sufficient to ensure a healthy life and reproductive, the emphasis should be placed on both the foods availability. This means the existence of a sufficient production quantity to meet global demand, of the food accessibility, that is the possibility to dispose of them by the self-production or an adequate income to purchase it. On the other hand, have adequate food stocks is a necessary, but not sufficient to achieve food security: we also need fair and effective distribution mechanisms.

Thus, it is immediate the connection with what economic theory shows: a market that is unable to establish a satisfactory balance between supply and demand, assigning the right price to the object exchanged, and which is not able to allocate the resources in order to maximize the satisfaction of operators, cannot be called an efficient market.

The recession in recent years, particularly at European level, has shown that, in a world increasingly open to global trade, it could not be disregarded by the market, both supply and those of the mouth, but not considering them as the ultimate goal, but rather tools to govern and to be used for the achievement of more socially acceptable purposes.

The main ambition of the pages that follow is precisely to try to make a systematic multidisciplinary approach on the conditions to ensure a sustainable well-being, starting from the concept of "food security."

As a consequence, in the following paragraphs we will try to investigate especially the economic dimension of sustainable well-being, with reference to the financial market and its rules, as well as the market of foodstuffs and the procedures for the formation of the price of those.

\section{Agricultural policies and the sustainable well-being}

We observe as a grave valuation error has been made by many policy makers in the past years, especially in more developed countries, believing achieved the status of food security and ending up to move the political action, not more towards a quantitative target, but only towards the production of higher value-added and more healthy (Henke and Salvioni, 2008). However, it is reasonable to assume that with an appropriate course correction in global politics, especially through coordinated action at global level, the adjustment of supply to demand growth, although difficult, is not impossible if jointly supported by research and innovation (De Castro, 2011). In general, however, the demand for food, where possible, meets with the offer of food composed of the products of farmers who follow sustainable practices (sustainable producers) and those that do not operate according to the principles of sustainability (no sustainable producers) (Manelli et al, 2014).

If so, how it should be, the question of survival is a priority, you cannot just here to give utmost importance to another question that is not primarily to produce more food, without which there would be no way in the well-being sought, nor what sustainable. It is equally true, however, that there are instruments intended to facilitate the achievement of this goal: among these tools will certainly include those businesses and markets, which are the primary subject of business studies.

This later aspect straight poses a pre-condition relating to the existence of an agricultural production system, identified as not only to adapt to new and higher level of demand, but to do so in compliance with environmental constraints, improving the quality of production and, above all, securing a satisfactory income business. 
On the other hand, to provide an adequate income from farming is indispensable to ensure the existence of the enterprise and the entrepreneur to persist in carrying out its activities. In fact, if the prerequisite for the survival of individuals is to have enough food, the condition for the existence of the company in general - and thus also of the agricultural - is that the latter is able to achieve a profit or loss, able to adequately remunerate the factors of production, namely labor and capital.

In a similar analysis perspective is no longer a proper theoretical interpretation of the entrepreneurial field that puts the antithesis - in a kind of irreconcilable conflict - the model of the "peasant" with the one of the "farmer capitalist" (Schneider, 2006). The overcoming of this antithesis between the two explained theoretical models happened in recent years, in a more concrete way, through the affirmation of a system of "entrepreneurial farmers," which must represent the corporate business on which to build sustainable well-being (Van der Ploeg, 2009). Infact, it is clear to all that the current agricultural crisis arises by insufficient production due to a demand that grows much more than it is able to grow the offer, but also from a market condition for which doing business in the agricultural sector does not ensure, in part because of unprofitable prices, a minimum level of income to survive the farmer and his family. This state of things, however, leads negative consequences: at first, maybe, a production of poor quality to reduce costs; then, the disappearance of the agricultural and the abandonment of its territory. So the economic, but also environmental consequences.

It is an asymmetry in some ways paradoxical: while there is a demand exceeding supply, the sale price does not meet the minimum income of the producers. It is then immediate recall to the market and to the task that economic science has always attributes and that is to form a balanced price between supply and demand. If the market for agricultural products is not the case, there are some conditions that prevent and these should be investigated to be overcome and/or removed.

There is no denying the existence of obvious imbalances in the markets for agricultural commodities. In general, infact, the prices at which farmers/entrepreneurs can sell their products tend to decrease, while the prices at which farmers themselves have to buy food, as consumers, consistently show up.

Without forgetting the phenomenon of so-called "land grabbing". The main reasons that led to the development of such phenomenon, already compared to the colonialism of past centuries, can be traced in the first place, right in the food supply and the volatility of agricultural prices. However, are not strangers to the land grabbing also economic and financial issues. The gradual increasing availability of liquidity, introduced in the global financial market to help overcome the economic crisis, in fact, led to increased attention on the part of large investors towards the use of capital in land acquisition. Finally, as a further cause of the race to land, the growth in demand for agroenergy should not be underestimated, which in addition puts all a matter of no small importance, when it becomes an alternative to the use of agricultural land for the food production.

To further expand imbalances, macroeconomic (between rich and poor countries) and microeconomic (between small and large enterprises), which are present in the market, also contributes to the role played by commercial intermediaries and retail trade figures normally associated with more developed countries.

The business model of multifunctional agricultural responds well, then, to some of the fundamental conditions of sustainable well-being, as it requires that the company reports in an appropriate way with the environment (protection of the landscape, land management, especially the rural, etc..), with the safety of products (health, diversification of food, etc..) and services (biodiversity protection, the farm) (Durand and Van Huylenbroeck, 2003).

Everything always in order to enable the achievement of a higher income for the entrepreneur, not only respecting the environmental constraints, but more by putting in place pro-active actions to improve the environment, to make it accessible and promote a culture of respect and protection. 
Figure 2. Dimensions and relationships of sustainable well-being

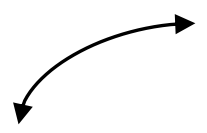

PERSONS SURVIVAL

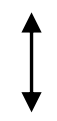

PUBLIC POLICIES OF ADDRESS AND SUPPORT

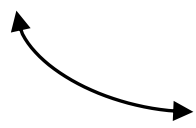

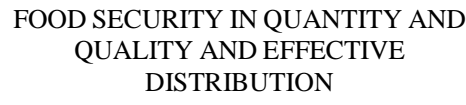
DISTRIBUTION

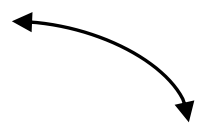

BALANCE MANAGEMENT OF FARMS

\section{SUSTAINABLE WELL-BEING}

\section{EFFICIENCY OF THE MARKET PRODUCT}

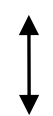

FAIR MARKET PRICE

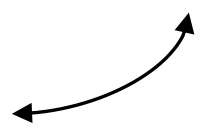

The above considerations allow you to define a logical scheme (Fig. 2) to better understand the various factors that affect the "sustainable well-being" in economic terms and, therefore, any action to achieve results.

\section{The enterprise balance and sustainable finance}

The balance in the management of an agricultural enterprise finds its concrete implementation in achieving a sufficient level of remuneration of the production factors, including the business community, and ultimately the growth of the value for the enterprise. If the ecological capital available, and where possible also its growth, represent a necessary condition for any possibility of farm survival (Van der Ploeg, 2009), the desired increase in food production is also derived from the use of external development tools provided by the market, especially the financial one, without necessarily having a dependency of the enterprise by the latter.

It is true that often, at first superficial analysis, the existence of a sustainable financial system for the agricultural enterprise is made to coincide with the availability of credit at low interest rates. By adopting such an approach, which happens quite frequently -, you commit two errors. First, we neglect the possibilities offered by the use of capital at risk for the full growth of the company, always imagining debt as the only viable way to finance that; Furthermore, it ignores the fact that, even before the presence of mechanisms of subsidized credit - however essential - you need to be able to count on the availability of valid and sustainable development projects both in terms of technical and production, both in the financial sector. In other words, the firm is able to create value - thus guaranteeing a future survival - if that makes investments through its contribution to production which are able to generate revenues in excess of costs over time (Manelli and Pace, 2009).

Beyond the indisputable scientific substantiation of these observations, past experience ${ }^{\dagger}$ has shown that a system of direct credit to farmers, at interest rates very low, does not automatically guarantee nor expansion of production or productivity growth, moreover it does not increase competitiveness in financial markets.

The presence of a contained cost of money, in fact, normally entails an excess in the credit application, even in the absence of a viable investment opportunities.

The failure of these initiatives has led to a review of funding policies to be adopted in favor of agricultural enterprises, leading to the construction of a support system based on three distinct levels (D'Amato, 2011):

- development of financial services tailored to the needs of the individual farmer;

\footnotetext{
† As part of a broad development program against hunger in the world, started in the 50s, and known as the "green revolution", they tried to introduce new farming techniques and new varieties of crops, especially in the largest countries in the developing , but with results considered by the most far from satisfactory (Dal Borgo, 2009).
} 
- identification of specialized financial intermediaries, able to direct, assist and support the system of agricultural enterprises in the process of access to capital markets;

- definition of strategies and policies for integrated global growth of rural areas. In summary, the sustainability of the financial system must be based on two pillars:

- the support that the broker makes in favor of the farmer, so that he can accurately define analytical and its plans and its financial programs to support the production strategy identified;

- the greater "personalization" of the financial instruments which can be adopted, in order to contain costs.

Bringing the analysis at the macro level, it can be argued, therefore, that in general all of the information asymmetries (those in the market to the enterprise to assign a value to non-tradable goods and that of the company to the market about the trend of the expected cash flows) leads to failure to provide all stakeholders (farmers, government, consumers, general public, etc..) the economic value generated by the agricultural sector as a whole. The problem of credit rationing caused by asymmetric information - and the consequent difficulty of access to capital - can find a solution, if only partial, in the "personalization" of the financial instrument offered to the entrepreneur. This is possible by making available to the intermediary system in some of the information needed to assess more accurately the investment to be made and then choosing the most suitable instrument for financing capital needs.

Finally, it is useful to note that the creation of a sustainable financial market should not be limited to only bring benefits to the farmer in the strict sense. In fact, the ultimate aim of an efficient financial system is to provide a path to finance the entire value chain of agricultural, supporting all the specific activities that can create economic value and competitive advantage of agricultural production (Porter, 1985). This means also involve the system of distribution and logistics, which have progressively taken over the last few years a decisive role in the agricultural sector. In fact, it should not be forgotten, that the system of agricultural finance is not static, recording, especially in recent years, continuous changes and developments, which is necessary to grasp the opportunities offered.

\section{The sustainable market of agricultural products}

In further analysis aimed at highlighting the conditions for the achievement of sustainable well-being, we intends to focus attention on the need to properly operate the market for agricultural commodities and, therefore, to make it capable of determining a fair price of the goods produced by firms.

On the other hand, the search for efficiency in the market should not and cannot be placed in an irreconcilable conflict with the goal of greater equity, in turn understood in the double sense of equality in opportunity and income. This is because the same inequality is a harbinger of the costs (social, administrative, etc.), which are the primary impediment to the achievement of maximum results with minimum effort. So the only viable solution to restore efficiency in the market is to enhance public goods, ie to assign the ownership of the goods that benefit specific individuals (in this case, farmers), and to connect it with adequate remuneration for their production. To put it more simply: you must pay the production of public goods. This choice "policy" will overcome the excesses and deficiencies of production which was mentioned before. The "non-excludability" of public goods (ie, the inability to exclude an individual from consuming the good), in fact, prevents that we can achieve efficiency through the creation of a dedicated market of the asset.

Moreover, the market situation of the agricultural commodities is quite well known. In fact, after the surge in prices recorded in 2007 and 2008, at present, the world agricultural markets still register higher price level than the pre-crisis period, despite a slight downturn to be charged to the global recession and the limited availability credit, factors which have led to a reduction in demand for food imports.

The medium-term forecasts confirm a scenario of instability, with a high probability of further increase in the price level. This is because all those structural conditions that caused the previous spikes in the price level persist. It should be noted that the rise in prices has already happened, as well as what is expected for the coming years, agricultural farmers, generally of small size did not benefit, nor presumably will benefit from it for the future, because, being mostly of small farmers being in a position to be a net buyers of food: so that the growth of prices determine on them only negative economic effects (Oxfam International, 2008). 
In addition, commodity high prices imply a fall in profit margins for the agricultural enterprise and, consequently, a greater difficulty in obtaining financial resources to undertake new investments aimed at innovations needed to production increases.

Added to this unlike what developing countries has been done, there is the behavior of industrialized countries that have increased their aid to agriculture, at the same time raising the level of protectionist barriers against imports through tariff, health and technical systems. The adoption of such a policies has come to prevent the consolidation of a proper system of competition, with the result that, failing farmers in poor countries to produce at competitive prices, there has been a gradual abandonment of agricultural production, affordable economically, making the same countries even more dependent on imports, and especially the most vulnerable to price volatility (Oxfam Italy, 2010).

In order to have an efficient and transparent commodities market with reliable prices it should be able to express, as noted, that the market itself is "liquid", that registers a significant number of exchanges, so that prices are not influenced by a few transactions. To make all this happen, it is essential the presence of numerous investors, including professional and commercial ones, which nevertheless alone would not be sufficient to properly operate the market. In fact, if, on the one hand, financial operators, acting as a counterpart, they ensure the necessary liquidity and, consequently, the high number of transactions, on the other hand, those business must ensure the market direction is moving towards correct quotes.

However, it cannot be considered unfamiliar to the continuous rise in prices in recent years, the circumstance that the goods market is going towards a substantial saturation, which would cause a gradual tightening of supply of commodities.

First, the explanation may be sought in increasingly higher levels of GDP on which we calculate the growth rates of the economy, in the face of some resources, however, which fell and more limited than in previous years; others, such as agricultural, in theory replicable over time, but with limited availability of cultivable land is a major constraint in many areas of the world (Centro Studi Confindustria, 2011). You guessed what impact has this condition of rigidity of the food security achievement, threatening to permanently affect the result of the sustainable well-being.

Then, there are other reasons can explain the arising prices deserving of mention. In particular:

- a continuing shift in global demand services to material goods, as a result of the growing weight of emerging countries on the global GDP;

- increased trade between countries caused by the relocation of the production process in searching of a labor costs reduction, resulting in vertical disintegration of value chains;

- a strong correlation between energy prices and those of other commodities, for which it is possible to show a similar trend in the demand curve for different commodities.

There are several proposals for action aimed at correcting the vulnerability of the food market: however, all require concrete action and a co-ordinating role of large international organizations that oversee the agricultural sector (FAO, IFAD and WFP) and who deal in general, the development of the economies (World Bank, IMF) and trade (WTO).

In schematic form, such interventions in the medium term include:

- the monitoring of the markets, in order to intervene promptly, or even prevent the crisis of agricultural prices;

- the elimination or at least reduction of all policies limiting imports and exports between countries;

- the control of the levels of supply, in order to optimize the management of the flows of production on the market;

- the adoption of appropriate policies for supporting and stabilizing the income of farmers.

If this condition is associated with market vulnerability, the entrepreneurial fragility of the agricultural sector, which consists mainly of small and very small businesses, we understand how difficult it is for a producer to argue their case on the market.

On the other hand, continuing to refer to the condition of little trading power, when the weakest subject - always a farmer - take the form of seller, in recent years, it is recorded the contrary circumstance with the progressive widening of the gap between recognized prices at producer, often set even below the cost of doing business, and those buying paid by buyers, whether they are producers or consumers. In fact, the contract weakness is not only about the relationship between countries, but also between actors in the supply chain, pushing retail prices to levels so low as to not be sustainable for those who fails to take advantage of scale economies or other logistical 
advantages like the large-scale distribution (GDO) (Follett, 2008). In this way, the progressive expansion of the industry has reached the point of some areas to reduce the effects of income multiplier of the agro-industrial sector.

So, from whatever angle you want to watch, the market for agricultural commodities is presented as a system characterized by a plurality of asymmetries inherent in the information available to the operators, the financial resources to put in place and, finally, the contract force held.

As already seen in the discussion of financial issues, even in this case the present asymmetries prevent attainment of a condition of market efficiency, requiring a corrective action that reactivates external mechanisms to achieve an overall balance. Therefore, it can identify two possible strategies to achieve a better functioning of the market, even in this case by placing them as the basis for the sustainability achievement:

- "to shorten the supply chain" of the operators, thus facilitating direct access to the market, even to smaller producers, of both sellers and buyers, and, at the same time, avoiding the large number of changes in ownership of production between intermediaries before reaching the final purchaser, which represent one of the causes for the artificial increase of prices;

- to encourage the entering into derivative contracts for large aggregations of producers, on one hand, to equip them with tools to hedge the risk of price volatility and, secondly, to trigger the described above mechanism of convergence between fixed prices and effective ones market recorded at future execution of those agreements.

With particular reference to the first point, we should note that, in addition to benefit from a more equitable remuneration of the producer due to the lower number of intermediaries, the benefits associated with supply chains "court" shall also cover the rural and local development, the productions protection and their link with the land, the cultural and productive traditions preservation, as well as the control of the organoleptic quality of the products (Sassatelli and Scott, 2001). Instead, while believed by many to be safe and very positive, the environmental effects of such a production and distribution organization are more uncertain, as they are related to the ability of operators to develop efficient logistics (ISFORT, 2013).

The "aggregative" solution, proposed as one of the strategies for achieving a sustainable market, requires the creation, on the one hand, of a network of the actors of the supply chains and, secondly, to physical or virtual places where it is possible to find farmers and distributors for the specific purpose of stimulating cooperation to reduce costs and to transmit knowledge (Morley et al., 2008).

However, as noted, while for many commodity there are future markets for many years now, for other trading can be spot, with the effective exchange of goods. So, more in detail, that we can actually achieve and make a derivatives market on commodities survive, assuming that there is the need by farmers - in their dual capacity as buyers or sellers - to hedge the risk of changes in prices, requires at least three conditions (D'Agostino, 2000):

- at least in some circumstances, the actual delivery of the underlying derivative commodity. This requires the asset shelf and its storage, thereby limiting agricultural products, the spaces for the construction of hedging transactions;

- the need to identify objectively the qualitative and quantitative characteristics of the underlying, with the consequent obligation to define in advance the standard features of the property to be exchanged;

- an appropriate level of competitiveness of the spot market, which allows the free floating of the commodity spot price. In fact, the presence of forms - direct or indirect - of control on prices or supply of the good would render meaningless the existence of the market and the presence of trading.

The essential first step to take is to not consider, however, the derivatives market as an area reserved for the few financial traders, or worse still demonize it. A first step to make it more transparent and therefore more accessible, it would be to follow the model adopted in the United States.

In this regard, it is useful to underline that empirically analyzing the relationship between the level and volatility of future prices of agricultural commodities and the amount of investments in derivative securities made by financial intermediaries (swap dealers and money managers), it shows that money managers investments follow the movements of prices, rather than to determine the trend, thereby reducing volatility. In contrast, swap dealers investments, which are less sensitive to changes in prices, accentuate the short-term fluctuations, at least for some markets (Borin and Di Nino, 2012).

In summary, the development of a market of futures, functional to requirements of a sustainable agricultural business system, requires:

- a sufficient number of operations such as to make it liquid and then potentially efficient; 
- a sufficient number of market makers (banks, brokers, etc.)., with appropriate operational structures;

- traders (producers, agribusiness firms and their combinations) with dimensions sufficient to support economic and operational commitments on the market;

- the development of a market "culture", the development of knowledge and through specific training.

It is clear that, beyond their theoretical merits, there is an open discussion about the measurability of the results obtained from the above two strategies - direct access to the market and aggregate management of derivative contracts - especially in the view of increasing complexity of markets and conditions of economic operators, including consumer preferences".

However, it is easy to understand as both the outlined above policy proposals require policies that favor the aggregation of farmers, especially the small ones, providing them with the bargaining power necessary to operate in usual contexts and for which they may not have neither expertise nor adequate resources.

The role of public decision-makers is crucial to achieve this through the adoption of specific policies that encourage the coordination of similar size operators.

In particular, we should not forget that the ultimate goal still remains to enable producers to achieve a profitable selling price of its activities - to promote their survival - in relation to the inputs costs, which are also to be kept at low levels.

However, such policies have already been adopted in previous years, but without results considered satisfactory. The first criticism has come from those who argue that to facilitate the supply concentration processes means to alter the competitive structure of the industry, with all the consequences in terms of prices.

For others, the reason of the failure of policy "aggregative" has traced the difficulty to control the supply, partly due to the ability of farmers to pass, in many cases, from a productive activity to another without having costs support associated with barriers to entry and / or exit (Distaso, 2002).

\section{Concluding remarks}

The sustainable well-being has dimensions overlapping and concentric with implications now especially supranational and therefore which would require a global effort. However, it remains a priority and the inescapable reminder of the need to ensure food security, first giving satisfaction to the need of humanity food: this is clearly a precondition for achieving the wanted sustainable well-being.

Moreover, the conviction is now increasingly widespread that, ultimately, producing food and preserve the landscape should represent the main form of employment of the labor force, in contrast to the current system of mere accumulation of capital that has caused high rates of urban unemployment and rural (Tudge, 2004; Van der Ploeg, 2009).

For the foregoing, the financial market, the market for goods and sustainable well-being will show which variables are strongly interconnected and through relations of mutual influence, according to the scheme proposed in Fig. 2.

In this perspective, it is necessary to immediately abandon a simplistic approach, but widespread, according to which speculation - especially the one of financial origin - is imagined as the predominant or even the sole cause of the seemingly irrational behavior recorded by the markets of commodities food, preventing the achievement of equilibrium conditions and at the same time penalizing weaker actors. And these behaviors relate not so much not only the trend of increasing prices of traded goods, especially as the strong fluctuations of the same, that, by setting a context of high uncertainty, make it difficult investment planning and consequently the achievement of productive objectives.

It is interesting to observe how the scientific studies on the field, accompanied by numerous empirical findings, showing that it is not possible to illustrate a direct link between speculation, rising prices and market volatility,

\footnotetext{
${ }^{\ddagger}$ For a comprehensive and thorough review of the literature on evaluation of sustainability in the agricultural sector, see the Rapporto Periodico of ISFORT n ${ }^{\circ} 18,2013$ at p. 65-67.
} 
especially in the short term ${ }^{\S}$. Conversely, the presence of professional traders seem to have favored a better functioning of the food commodities market, increasing liquidity in terms of growth of the probability of execution of operations, to the point of being able to say that the absence of speculation would put at risk the existence of the market. Furthermore, the increased operations of the market and the increasing abundance of trading favor undoubtedly the dissemination of information, limiting price fluctuations and preventing the achievement of extreme peaks (Bauer and Minsch, 2013).

In order to substantiate these considerations necessary to refer to the historical data of the price of the food is provided by the FAO as for price trend, as for the intensity of the fluctuations of the same. Well, if it is true that in 2008 and 2012, the level of prices recorded the most significant peaks, expanding the horizon of observation, we note that (Bauer and Minsch, 2013):

- 1990 to 2000, there were no significant or no sudden changes in the price level;

- going back to the beginning of the $\mathrm{XX}^{\circ}$ century, agricultural commodities have become much more affordable over time, to the point of today to have a real price lower by about $50 \%$ than that of a century ago;

- we come to similar conclusions in relation to price volatility, as in the past five years, since 2007 , the phenomenon in question was certainly very intense, but when you consider what happened in the last fifty years, it can be said that the volatility in the 70's was far superior to the current one.

Instead, what surely has produced a large increase in price volatility and decisions were unilateral policies of some countries, directed towards the introduction of diversified forms of protectionism (restriction of exports, application of customs duties, etc.). Without such choices as the result of agreements worldwide, but only with the stated goal of a defense of its agriculture, the defense that has come to be systematically useless, if not harmful, as a result of adaptations in the markets, as for the agricultural commodity as for the financial one, immediately after the adoption of those decisions.

The inefficiency of markets and price volatility recorded in recent years, especially during the most acute crisis of 1997-2003, have led many farms to adopt "defensive" strategies, often proved inadequate to achieve the required objectives to the achievement of sustainable well-being, in terms of quantity and quality of food products. In particular, in a context of strong uncertainty it was decided to pursue short-term profit at the expense of a more farsighted pursuit of value creation, even going so far as to threaten the company survival.

However, there was, who contrary to what is shown above, preferred to give a time horizon of long-term in responding to the met difficulties: the more acute the crisis occurred, the greater is the investment in the company, in order not so immediately get the maximum profit, but rather to ensure, firstly, the survival of the company, and then, to increase the overall company value by increasing the quantity and quality of production, to compete properly on the world market.

Today, these "farmers entrepreneurs" are in the best position to deal with a future even if full of uncertainty: in fact, they can rely on quality products, on multifunctionality and the right manufacturing company size to support the global competition.

\section{References}

Bauer P. e Minsch R., (2013), “Commercio di materie prime agricole: croce o delizia?”, in Economiesuisse, n ${ }^{4}$, 18 marzo, p. 1-12.

Borin A. e Di Nino V., (2012), "The role of financial investments in agricultural commodity derivatives markets", Temi di discussione ${ }^{\circ} 849$, Banca d'Italia, gennaio, www.bancaditalia.it/pubblicazioni/econo/temidi/td12/td849_12/td849/.

Centro Studi Confindustria, (2011), "Materie prime, limiti alla crescita e difficoltà per le imprese italiane”, Working Paper $n^{\circ} 60$, giugno, Roma, p. $5-20,35$

Cesaretti G.P., Viola I., Misso R. e Borrelli I. P. (2013), "Green society - A conceptual framework of sustainability from a territorial perspective", in Quality - Access to Success, Settembre, Supplement, Vol. 14, p. 50.

${ }^{\S}$ A comprehensive review of empirical studies on the topic, published between 2010 and 2012, is reported in a contribution of Will MG, Prehn S., I. Pies and Glauben T., (2012), " Schadet oder nützt die finanzspekulation mit agrarrohstoffen? - Ein literaturüberblick zum aktuellen stand der empirischen forschung ", Discussion Paper No. 2012-26, Martin Luther Universität Halle-Wittenberg. 
D’Agostino V., (2000), “Commodities e managed futures”, in www.tesionline.it/_PDF/9315/9315p.pdf, Libera Università Internazionale di Studi Sociali G. Carli, Roma, p. 9-18.

D’Amato R., (2011), “Agricoltura e finanza rurale”, elaborato finale del corso di "Cooperazione per l'autosviluppo”, c/o Dipartimento di Scienze Politiche, Università degli Studi di Bari, in www.futurbaggio.com/wp-content/data/rdamato, p. 2-9.

De Castro P., (2011), "La corsa alla terra, Cibo e agricoltura nell'era della nuova scarsità", Donzelli editore, Roma, p. 9.

Distaso M., (2002), “Lezione 3. Comportamento dell'impresa agricola nel mercato della produzione”, in Lezioni di Economia e Politica agraria, a. a. 2002-2003, Università degli studi di Bari, www.dse.uniba.it/Corsi/docenti/Distaso/Lezione\%203.

Durand G. e Van Huylenbroeck G., (2003), "Multifunctionality and rural development: general framework", in Van Huylenbroeck G. e Durand G., Multifunctional agriculture. A new paradigm for European agriculture and rural development, Ashgate, Burlington VT (USA) e Adelrshort (UK).

Elkington J., (1997), "Cannibals with forks: the triple bottom line of $21^{\text {st }}$ century business", Capstone, Oxford.

Follett J. R., (2008), "Choosing a food future: differentiating among alternative food options", in Journal of agricultural and environmental ethics, vol. $\mathrm{n}^{\circ} 22$, pp. 31-51.

Henke R. e Salvioni C., (2008), "La multifunzionalità in agricoltura: dal post-produttivismo all'azienda rurale", in Agricoltura multifunzionale. Comportamenti e strategie imprenditoriali alla ricerca della diversificazione, Studi \& Ricerche INEA, Edizioni Scientifiche Italiane, Napoli, p. 13-29.

ISFORT, (2013), "La sostenibilità delle filiere agroalimentari. Valutazione degli impatti e inquadramento delle politiche", Rapporti periodici, $\mathrm{n}^{\circ}$ 18, Roma, p. 59-65.

Johnson H., (2004), "Subsistence and control: the persistence of the peasantry in the developing world", in Undercurrent, vol. 1, 1, pp. 55-65.

Lang T. e Heasman M., (2004), "Food wars: the global battle for mouths, minds and markets", Earthscan, London/Sterling Usa.

Manelli A., Domenichelli O. e Vallesi M., (2014), "Learning from the financial crisis to achieve a sustainable agricultural system", in Rivista di studi sulla Sostenibilità, $\mathrm{n}^{\circ} 1$, Franco Angeli, Milano.

Manelli A. e Pace R., (2009), "Finanza di impresa”. ISEDI, Novara, p. 8-13, 34.

Morley A., Morgan S. e Morgan K., (2008), "Food hubs: the «Missing Middle» of the local food infrastructure", BRASS Center, Cardiff University, (www.brass.cf.ac.uk/uploads/Food_HubKM0908.pdf).

OXFAM International, (2008), "Double-edge prices: lessons from food price crisis - 10 actions developing countries should take", briefing paper 121, Oxford.

OXFAM Italia, (2010), “Insieme contro la fame: ricette globali per un'azione vincente”, Documento di approfondimento, ottobre, Arezzo, p. 1317.

Porter M., (1985), “Competitive Advantage: creating and sustaining superior performance”, Free Press, New York, 1985.

Sassatelli R. e Scott A., (2001), "Novel food, new markets and trust regimes: responses to the erosion of consumers' confidence in Austria, Italy e U.K." in European Societies, vol. 3, n 2, p. 213-244.

Schneider S., (2006), "A diversidade da agricultura familiar”, UFRGS Editora, Porte Alegre, Brasile.

Sogesid, (2014), in www.sogesid.it/sviluppo_sostenibile.

Tudge C., (2004), "So shall we reap: what's gone wrong with the world's food - and how to fix it", Penguin Books, New York.

Van der Ploeg J.D., (2009), "I nuovi contadini. Le campagne e le risposte alla globalizzazione”, Donzelli Editore, Roma. 